\title{
MULHERES FALANDO SOBRE SUAS CRENÇAS E PRÁTICAS NO CUIDADO AO COTO UMBILICAL DO RECÉM-NASCIDO *
}

\author{
Astrid Eggert Boehs ** \\ Marisa Monticelli ** \\ Ingrid Elsen $* * *$
}

\begin{abstract}
RESUMO - Este estudo teve como objetivo verificar o significado do coto umbilical, o aux́lio à nova mãe no cuidado ao $\mathrm{RN}$ e as práticas no cuidado ao coto umbilical. Utilizou-se técnicas qualitativas para entrevistar mulheres com experiência no cuidado ao RN. Verificou-se que o aux́lio no cuidado ao RN é feito pelos familiares de forma hierárquica onde a mãe da puérpura ocupa primeiro lugar. Este auxílio irá influenciar na percepção que a nova mãe tem coto bem como nas práticas do cuidado. Conclui-se que a Enfermangem, no processo de cuidar deve levar em consideração a família e as percepções desta, para que possa haver diálogo e respeito mútuo.
\end{abstract}

\begin{abstract}
The goal of this study was to verify the meaning of the umbilical stump, the help offered the new mother in caring of her newborn, and practices concerning the umbilical stump care. Qualitative techniques were employed to interview experienced on newborn care. It has been verified one conclusion arrived at is that the help invested on newborn care is performed by the family according to an hierarchical form whereby the puérpera's mother occupies first place. Such help will influence the new mother's perception of the umbilical stump, as well as her care practices. Thus nursing, in the context of its caring process, must take into consideration the family and its perceptions so that dialogue and mutual respect will be are expected to prevail.
\end{abstract}

\section{INTRODUÇÃO}

Na nossa vivência como enfermeiras, trabalhando em instituiçōes de saúde, deparamo-nos constantemente com as diferenças entre as nossas concepções sobre saúde e cuidado e as da população que atendemos. Temos observado, através da nossa experiência em maternidade, que os profissionais de saúde ${ }^{1}$ e as mulheres que procuram os serviços, têm crenças, práticas e portanto linguagens diferentes, dificultando assim o processo de troca de experiência tão importante na assistência. Mesmo existindo uma "vontade" de modificar esta situação, os profissionais de saúde, principalmente a equipe de enfermagem, sentem-se impotentes no tratamento desse problema. Qual o caminho à seguir para que estas mulheres e os profissionais de saúde tornem-se co-participantes no processo? Será que os profissionais de saúde conseguem uma aproximação do conhecimento popular na prestação de cuidados ao RN?

Estes questionamentos nos motivaram, durante o período de $1987 / 88$ a realizar uma pesquisa com relação às percepções das mães sobre os cuidados prestados à criança no primeiro mês de vida (MONTICELLI \& BOEHS ${ }^{14}$.). Verificou-se neste estudo que, entre todos os cuidados a serem prestados ao RN, o coto umbilical foi a maior fonte de dúvidas e preocupaçōes no que se referia ao cuidado. Além disso, percebemos que era em relação ao coto umbilical que as mães tinham maior número de práticas e crenças que nós não conhecíamos e não sabíamos explicá-las.

Entre as crenças que emergiram mais frequentemente, uma era a de que o coto umbilical, após a que$\mathrm{da}$, ainda continuava influenciando na vida de crianças ou até mesmo na de outras pessoas. Percebemos tamberm que outros cuidados ao RN, como o banho e a troca de fraldas inspiravam medo enquanto a criança ainda estivesse com o coto umbilical.

Mediante estas preocupações, as mães afirmavam que precisavam de uma pessoa experiente para ajudálas no cuidado ao RN, especialmente durante este período. Esta pessoa experiente é que faria também o curativo do coto, sendo que, muitas vazes, o curativo era feito de forma diferente daquela que nós ensinávamos na maternidade.

$\mathrm{Na}$ literatura, tamberm encontramos trabalhos como o de ARAÚJO ${ }^{2}$, COSMINSK ${ }^{5}$, SPENCER ${ }^{17}$ e MEAD ${ }^{12}$ que referem ser o coto umbilical fonte de preocupações e crenças. Estas crenças estão ligadas com a prevenção contra o mal, como o futuro da

\footnotetext{
* Prêmio Laf́s Netto dos Reis - $1 \%$ lugar - 42 Congresso Brasileiro de Enfermagem - Natal - RN.

** Professores Adjuntos do Departamento de Enfermagem da UFSC.

*** Professor Adjunto do curso de Pós-Graduação em Enfermagem daUFSC e Orientadora do Trabalho.
} 
criança e outros. DALILLA ${ }^{7}$ observou que há receio por parte das mães de que possa ocorrer acidentes de vários tipos para explicar o medo antecipado de cuidar do coto umbilical.

Diante destas constatações, nos perguntamos: $O$ que significa o coto umbilical para a população que atendemos na matemidade ? Quem são estas pessoas experientes que as mães referem ? Quais as experiências, no que se refere ao cuidado, que elas ensinam para as gerações mais novas?

Isto originou um novo estudo envolvendo mães multiparas e primiparas, familiares, e ainda pessoas significativas como vizinha, comadre e outros.

A pesquisa teve como objetivos específicos:

- compreender o que significa o coto umbilical para a população estudada. bilical.

- identificar qual o cuidado prestado ao coto um-

- identificar quem auxilia nos cuidados ao RN enquanto este ainda está com coto umbilical.

Consideramos este estudo uma importante contribuição para a enfermagem, principalmente da área materno-infantil, porque abordamos as percepções das puérperas, seus familiares e outros significantes que estão ou estiveram envolvidos no cuidado do coto umbilical. Acreditamos que estes dados serão subsídios úteis para a equipe de saúde que desenvolve atividades em matemidades, serviços de pré-natal, postos de saúde e ambulatório, uma vez que, conhecendo a percepção da população sobre o cuidado do $\mathrm{RN}$, os profissionais não atuarão mais de forma unilateral e autoritária. Para que exista co-participação no processo educativo, todas as fontes de conhecimento devem ser consideradas. Esta pesquisa deverá servir para que a equipe de saúde recupere o conhecimento das mães no cuidado dispensado a seus filhos e para que se concientizem de que esses valores e crenças são indispensáveis na prestação da assistência.

\section{METODOLOGIA}

Para aprofundar as nossas questões resolvemos fazer um estudo exploratório, utilizando técnicas qualitativas para a coleta e análise dos dados, o que a nosso ver nos proporcionaria uma compreensão maior das experiências das mulheres.

A coleta de dados foi realizada no primeiro semestre de 1988, na mesma matemidade onde já tínhamos realizado o estudo anterior e onde já atuávamos como enfermeiras-docentes. Esta matemidade se situa na parte insular da cidade e mantém convênio com o Instituto de Assistência e Previdência Social (INAMPS) e Universidade Federal de Santa Catarina (UFSC). Possui um total de 47 leitos de puérperio onde são intermadas puérperas de institutos previdenciários e ainda puérperas sem qualquer vínculo com seguros de saúde ou cooperativas. É a matemidade onde existe maior demanda de parturientes do município.

Antes de iniciar o estudo na matemidade, entregamos o projeto à direção da mesma, que concedeu autorização para a utililização do campo de pesquisa. Os funcionários das unidades foram informados verbalmente sobre as nossas atividades.
$\mathrm{O}$ anonimato da maternidade foi considerado, não se fazendo constar o nome da mesma no projeto, relatorio, ou qualquer publicação ou ainda no dado de pesquisa. $\mathrm{O}$ anonimato das pacientes foi garantido na coleta dos dados e relatório, não se fazendo constar o nome dos mesmos.

A coleta de dados foi realizada através de entrevistas individuais com as mulheres, na propria unidade de internação obstétrica, geralmente o horário de visitas. Isto acontecia mediante uma conversa informal onde nos apresentávamos, e fazíamos então o pedido para participar da entrevista. Havendo concordância e dependendo da situação, procurávamos o ambiente mais tranquilo e mais confortável da unidade para entrevista.

As entrevistas eram sustentadas por um roteiro guia, que foi elaborado a partir dos dados da pesquisa anterior. (MONTICELLI \& BOEHS, 1988). Este roteiro continha os seguintes ítens:

1 - O que é "umbigo" (coto/cordão) e para que serve ? Por que?

2 - O que faz com o "umbigo" (coto) depois de cair ? Por que ?

3 - Cuidados com o "umbigo" (coto) curativo: solução usada e modo de fazer o curativo, incluindo a utilização ou não da faixa umbilical.

4 - Outros cuidados com as crianças enquanto esta ainda está com o coto umbilical.

5 - Ponto de referência ou ajuda no cuidado à criança, enquanto esta ainda está com o coto umbilical; Quem ajuda a puérpera ? O que é esta ajuda: ensino, auxilio ou fazer por?

Estas questões, portanto, serviam de guia para nortear o encaminhamento da entrevista e para que não nos desviássemos dos objetivos propostos, porém a conversa era flexível conforme os dados fossem surgindo.

Durante a entrevista registrávamos as idéias principais num papel rascunho, e logo após saíamos da unidade e escrevíamos os detalhes da conversa na íntegra, reconstituindo os diálogos e usando a linguagem da entrevistada.

Apos toda a descrição da entrevista, elaborávamos o que denominávamos de reflexões do observador, que se constituiam de notas téricas e metodologicas. Nas teóricas registrávamos nossas reflexões sobre o conteúdo da entrevista. Estas notas auxiliavam a direcionar a entrevista seguinte e se constituíram num material rico para realizar a analise dos dados:

“. . . a questão da dádiva divina aparece pela primeira vez numa entrevista ... . essa mulher cita como se isso realmente explicasse o sentido do umbigo. Deus - umbigo - vida. O umbigo é símbolo da vida".

Nas notas metodológicas registrávamos as nossas impressões gerais sobre como transcorreu a entrevista, o comportamento da mulher entrevistada e as possíveis interferências durante a conversa. Estas notas nos auxiliavam na condução das entrevistas subsequentes: 
"creio que minha abordagem não foi muito correta. Conversei primeiro com a mãe e filha juntas ... deveria ter entrevistado cada uma em separado ....".

Não utilizamos gravador por acharmos que isto tiraria a naturalidade da nossa entrevista, além de exigir um ambiente mais privativo.

A população estudada se constituiu de 30 mulheres e o principal critério de escolha foi a experiência no cuidado ao RN e a vontade de participar do estudo. Entre elas, havia 9 primiparas e 21 multiparas, sendo que algumas eram puérperas, outras eram mães, sogras, avós, tias de puérperas e ainda outras eram pessoas significativas, como vizinha, comadre, conhecida. Todas residiam na região da grande Florianópolis que corresponde ao município de Florianópolis e municípios vizinhos. A idade variou entre 18 a 67 anos e o nível de escolaridade foi desde analfabeto até primeiro grau completo.

A análise foi efetuada de forma concomitante com a coleta. A medida que determinados assuntos se delinearam entre os dados, estes foram agrupados em categorias e a partir daí aprofundados em entrevistas subsequente. A partir das categorias que emergiram, identificamos os temas. A coleta de dados foi encerrada com a saturação teórica. Segundo GLASER \& STRAUSS ${ }^{9}$, saturação teórica é o momento no qual novas categorias param de surgir nos dados.

\section{RESULTADOS}

Dos dados coletados emergiram três temas principais que mantinham relaçōes entre si e que foram intitulados:

- Significado do umbigo;

- Ajuda no cuidado ao RN;

- Mudança nos cuidados do coto umbilical.

$\mathrm{O}$ "umbigo" tem vários significados para as mães. Algumas o veêm como algo perigoso para a criança e que pode levá-la à morte se não for bem cuidado;

"O umbigo (coto umbilical) é uma coisa que a gente tem que cuidar muito porque se não, a criança pode ate morrer". (mulher de 54 anos, 11 filhos, mãe de puérpera).

"As parteiras disseram que podia sangrar bastante e a criança morrer". (mulher de 60 anos, 2 filhos, sogra de puérpera).

Algumas entrevistadas referindo-se de uma forma indistinta às palavras coto e cordão umbilical, fizeram uma referência de ordem espiritual ligada à vida da criança:

"E a dádiva divina. Se Deus criou a vida e se o cordão é vida, é porque ele queria que a criança vivesse". (mulher de 22 anos, 2 filhos, puérpera).

"É a alma da criança porque foi Deus que escolheu que esta criança sobrevivesse através do umbigo". (mulher de 53 anos, 5 filhos, sogra de puérpera).

Outras, referindo-se ao "umbigo" deram uma explicação de ordem natural ou orgânica:

"É um pedaço de pele que serve para ele se alimentar quando está dentro da gente". (mulher de 53 anos, 8 filhos, vizinha de puérpera).
“. . . acho que é pra criança respirar dentro da mãe, pelo sangue né ? (mulher de 57 anos, 5 filhos, sogra de puerpera).

As mulheres que aguardam o coto umbilical de seus filhos apresentaram diferentes razões para este procedimento:

"Eu já disse que se o umbigo é a vida da criança é como guardar a vida, é o símbolo da vida .... então a gente não deve se desfazer dele". (mulher de 53 anos, 5 filho, sogra de puérpera).

DOUGLAS ${ }^{8}$ refere que o perigo está nos estados de transição, simplesmente porque não é um estado, nem é o seguinte, ele é indefinível. Nós entendemos que o coto umbilical está neste estado de transição pois já foi vida enquanto cordão, que ligado à placenta, tinha a função de nutrir o feto proporcionando-lhe a vida. Depois, quando a criança nasce, o coto umbilical ainda permanece no corpo da criança por aproximadamente 7 dias. Durante este período o mesmo apos a queda, este coto tem um poder de perigo e morte como tamberm poder com relação a vida, como vimos nos depoimentos das mulheres entrevistadas.

Outras mulheres guardam o coto umbilical após a queda, para fins terapêuticos:

"Faço um chá com o umbigo para aliviar a inquietude da criança com bronquite". (mulher de 36 anos, 6 filhos, immã de puérpera).

"Guardo prá fazer simpatia contra doença". (mulher de 63 anos, 6 filhos, av6 de puérpera e parteira).

Algumas mulheres guardam o côto umbilical porque considera-no como algo que pode influenciar na saúde ou ainda, resguardar a vida:

"Se a gente não guardar, a criança ou a mãe podem morrer". (mulher de 22 anos, puérpera, primipara)

"Tem que guardar porque é uma coisa santa que protege a saúde da criança". (mulher de 21 anos, puérpera, primipara).

$\mathrm{Na}$ literatura encontramos o trabalho de SPENCER 17 relatando que na Austrália a mulher Aranda faz um colar com o pedaço do coto umbilical colocando no pescoço da criança para prevenir doenças. Ainda segundo DOUGLAS ${ }^{8}$ o refugo físico como pele, unhas, mexas de cabelo estão em estado de margem que suscita poder e perigo. Poderíamos inferir aqui que o coto constitui-se neste estado de margem e que tem o poder sobre a saúde ou doença da criança.

Para outro grupo de entrevistadas o coto umbilical era guardado como lembrança da gravidez ou como afirmação do papel de mãe:

"De vez em quando eu olho e fico pensando que eles saíram de dentro de mim, parece que me afirmo mais como mãe". (mulher de 54 anos, 8 filhos, mãe puérpera).

"O meu filho mais velho sempre diz que quando eu morrer ele vai ficar com o pedaço de cordão que era dele". (mulher de 
50 anos, 8 filhos, amiga de puérpera).

"Guardei de lembrança prá quando eles crescerem. Acho que gostariam de ter um pedaço deles, de quando eram pequenos". (mulher de 54 anos, 11 filhos, mães de puérpera).

Outras entrevistadas ainda, deram um destino diferente ao coto, demonstrando no entanto sua vinculação com a futura profissão ou ocupação da criança:

"Eu pico em pedacinhos e coloco num livro que é prá criança ficar inteligente". (mulher de 60 anos, 2 filhos, sogra de puérpera).

"Eu queimo para o rato não pegar porque se pegar o filho fica ladrão ... e o que dizem os antigos". (mulher de 52 anos, 3 filhos, mãe de puérpera).

ARAÚJO ${ }^{2}$ em seu trabalho realizado em uma pequena cidade Alagoana às margens do Rio são Francisco, refere que a população mantém inúmeras crenças nas quais o coto umbilical está ligado a futura ocupação da criança. Refere tambêm que uma criança muito popular é que o coto deve ser muito bem guardado pois se o. rato roer, a criança será no futuro um ladrão. MEAD ${ }^{12}$ numa pesquisa entre os Arapesch e COSMINSKY ${ }^{5}$ na Guatemala também monstram que o destino do cordão, placenta e coto umbilical estão ligados com crenças sobre o futuro da criança.

Outras mulheres entrevistadas para este trabalho deram um destino ao coto, porém não sabiam o motivo deste procedimento:

"Os umbigos dos meus filhos eu enterrei para nenhum bicho comer. Porque ?... eu não seu dizer ..." (mulher de 55 anos, 9 filhos, mãe de puérpera).

"Eu enterro mas não sei porque. nunca pensei nisso ..." (mulher de 18 anos, 1 fillho, puérpera).

Porém nem todas as mulheres se preocupam com o destino do coto. Estas jogam-no simplesmente fora apos a queda, traduzindo que este coto nada significa para elas:

"Acho que não precisamos mais não é ?

Tem gente que guarda ... mas eu não vejo significado nisto". (mulher de 40 anos, 2 filhos, mãe de puérpera).

"Jogo fora porque não acredito nas crendices da sogra que dizia que devia enterrar no galinheiro ou que filha que cortar o umbigo em pedacinhos para a criança ficar alfaiate quando crescer". (mulher de 41 anos, 3 filhos, mãe de puérpera).

Os depoimentos das entrevistadas que referiam o "umbigo" como sem significado, fizeram menção de que outras pessoas o guardavam, mostrando assim que já ouviram sobre a significação do coto.

O segundo tema ajuda no cuidado ao RN emergiu, para nós, pesquisadoras, como uma questão centralizadora, uma vez que esta ajuda será a geradora dos significados acerca do "umbigo" do RN para a puérpera, bem como influenciadora do cuidado tera- pêutico dispensado ao coto umbilical.

Os dados coletados são permeados por duas importantes questões: quem dá ajuda e qual o tipo de ajuda. A mãe da puérpera aparece em primeiro lugar na ordem daquelas que ajudam a cuidar do RN enquanto este ainda está com o coto umbilical e fazem o curativo do mesmo. Para algumas, estas orientações já foram feitas ao longo da vida.

"Minha mãe mostrou nos meus irmãos pequenos o que deveria ser feito. É o que de melhor uma mãe pode deixar para a filha". (mulher de 36 anos, 6 filhos, puerrpera).

Após o nascimento da criança, é a mãe da puérpera quem faz os cuidados, como podemos veriricar nestes depoimentos:

"Eu cuido do umbigo do nenê até o décimo dia porque minha filha tem medo de mexer". (mulher de 50 anos, 8 filhos, mãe de puérpera).

"Minha mãe não deixa eu fazer o curativo. É ela quem faz por que é muito coruja". (mulher de 27 anos, 3 filhos, puérpera).

Percebemos que somente na ausência da mãe da puérpera é que o lugar é ocupado pela sogra ou então pela irmã mais velha, pela avó, vizinha, existindo portanto uma certa hierarquia nesta ajuda:

"Aprendi com a sogra, pois minha mãe mora longe". (mulher de 41 anos, 3 filhos, puérpera).

"Eu ajudo minha vizinha. A gente que ê pobre tem que se dar as mãos". (mulher de 53 anos, 8 filhos, vizinha de puérpera). “. . . a minha irmã que vai cuidar. Ela tem experiência". (mulher de 36 anos, primípara, puérpera).

Os profissionais de saúde foram algumas vezes lembrados e citados. As parteiras leigas eram mencionadas como fonte de ajuda pelas mulheres mais idosas:

"Aprendi o curativo do umbigo com uma parteira alemã muito boa". (mulher de 50 anos, 8 filhos, mãe de puérpera).

Em relação ao tipo de ajuda solicitado pela puérpera, as "mulheres experientes" da famnlia tanto aconselham a mesma no que diz respeito ao cuidado direto do $\mathrm{RN}$, fazendo o curativo do coto ou dando banho, bem como ajuda nos afazeres domésticos:

"Minha māe ajuda a lavar a roupa e a cuidar do umbigo do nenê. As outras coisas eu faço". (mulher de 27 anos, multípara, puérpera). tações:

O tipo de ajuda da enfermeira se limitou a orien-

"A enfermeira falou que era prá passar merthiolate". (mulher de 20 anos, primípara, puérpera).

A parteira leiga foi mencionada pelas mulheres mais idosas como fonte de conselhos como de ajuda substancial no cuidado ao RN:

"A parteira fazia o curativo todos os dias e examinava sempre o nenê de corpo in- 
teiro. Ia 9 dias na casa". (mulher de 63 anos, 6 fillhos, avó de puérpera).

Segundo RODRIGUES ${ }^{15}$ o RN encontra-se numa situação de dualidade, pois está simultaneamente na natureza e na cultura. Além disso, ele está ainda com o coto umbilical uma parte do corpo que está num estado de transição e segundo DOUGLAS ${ }^{8}$ estes estados suscitam muitas crenças e mitos. Assim mãe procura uma pessoa mais experiente para fazer aquilo que lhe inspira medo. Verificamos tamberm que as mães e as sogras consideram um dever fornecer esta ajuda:

“É um dever explicar tudo porque ela não tem mãe". (mulher de 53 anos, 5 filhos, sogra de puérpera).

"Vou ensinar, vou mostrar como se faz e depois acho que ela mesma vai ter que fazer. É meu neto, mas é filho dela". (mulher de 40 anos, 2 filhos, mãe de puérpera).

Os dados encontrados neste trabalho estão de acordo com outro realizado pelas autoras MONTICELLI \& BOEHS ${ }^{14}$ onde as mães referem que precisam do auxílio de uma pessoa experiente, sendo que esta pessoa experiente é com maior freqüência a mãe da puérpera.

Num trabalho realizado por ELSEN \& ALTHOFF ${ }^{6}$, sobre o suporte social no ciclo grávido puerperal com a população de origem açoriana na Costa da Lagoa, Florianópolis verificou-se que, assim que a criança nasce, as mulheres mais experientes da familia desempenham um papel relevante como suporte social. São elas que ajudam nos afazeres domésticos e é a mãe e a sogra que dão conselhos sobre como cuidar da criança e do côto umbilical.

CARTANA ${ }^{4}$ refere em seu trabalho realizado também na Costa da Lagoa, que a população considera a famnlia "as pessoas do coração" isto é, pessoas ligadas efetivamente. Assim, quem ajuda a puérpera no cuidado do RN e outros afazeres da casa, são as mulheres que são "do coração".

Conforme BOEHS ${ }^{3}$, num trabalho realizado com familias de primíparas de origem açoriana em Florianopolis - SC, as famnlias proporcionam ao novo casal auxflio material como: moradia, movveis, e quando nasce o primeiro filho deste, as mulheres destas familias de origem auxiliam no cuidado ao RN.

Como constatado até aqui, as pessoas requisitadas para auxiliar nos cuidados ao RN são em primeiro lugar as pessoas experientes ligadas efetivamente à nova mãe sendo que os profissionais do sistema formal de saúde foram mencionadas numa proporção menor. porém, a âtual realidade é a de que os partos são feitos na sua maioria, nas maternidades, e isto é valorizado pelas mulheres.

Esta valorização tem levado a mudanças na forma de cuidar do coto umbilical. As mudanças mais freqüentes são quanto ao tipo de solução utilizada para o curativo do coto e quanto ao uso e desuso da faixa umbilical.

As mulheres mais idosas e provenientes do interior do estado referiam o uso de azeite de oliva como substância mais utilizada, porém, se este faltasse, poderia utilizar qualquer outro tipo de 6leo. Algumas ve- zes também este bleo era associado a outros produtos, sendo que as explicações do uso são as mais variadas.

"Uso azeite com mel porque o azeite não deixa o umbigo ficar ressequido e o mel é um santo remédio prá resfriado, cólica e uma porção de cosias". (mulher de 57 anos, 5 filhos, sogra de puérpera).

"Eu pego um paninho bem limpo e aqueço óleo doce ou mesmo óleo de cozinha e ponho no umbigo uma vez por dia. Todo o dia, antes de botar o azeite no paninho eu assopro o azeite prá ficar bem quentinho, depois boto o bleo e embrulho no umbigo. Sempre deu certo". (mulher de 53 anos, 8 filhos, vizinha de puérpera).

Os mercuriais orgânicos também são utilizados para antissepsia do coto umbilical. O mercúrio cromo é utilizado pelas mulheres na faixa de 36 a 52 anos. Faz-se com frequêencia a associação com o p6 de sulfa. "Eu uso mercúrio e po de sulfa porque a parteira me ensinou". (mulher de 55 anos, 9 filhos, mãe de puérpera).

Entre as mulheres mais jovens, de 18 a 30 anos, a substância mais utilizada para a realização do curativo umbilical foi merthiolate, que em algumas ocasiōes também, é usado em associações ao pó de sulfa.

Percebe-se que a substância variou de acordo com a idade das mulheres. As mães idosas utilizam "azeite", fruto das orientações, principalmente de parteiras leigas, quando estas faziam os partos à domicílio. As mulheres mais jovens utilizam o mercúrio cromo que é um mercurial orgânico como solução antesséptica, ainda hoje largamente utilizado nas instituições, apesar da sua contra-indicação, segundo normas do Instituto Nacional da Assistência Médica e Previdência Social (INAMPS). Segundo o MINISTÉRIO DA SAÚDE ${ }^{13}$, os mercúrios orgânicos são considerados inadequados como antissépticos. Estudos realizados demonstram que esses compostos são apenas bacteriostáticos e sofrem inativação quando em contrato com pele ou mucosa. Acresce ainda que os mercuriais orgânicos em solução aquosa, se contaminam com pseudomonas, e suas soluções alcoblicas são menos ativas do que o próprio álcool.

As mulheres mais jovens utilizam o merthiolate como solução antisséptica, que também é um mercurial orgânico, portanto, com as mesmas contra-indicações que o mercúrio cromo. Porém, ainda é uma orientação para o curativo do coto umbilical nas instituições de saúde e nos consultórios médicos. O po de sulfa, apesar de largamente referido não é uma orientação da bibliografia especializada e não é uma orientação das instituições de saúde.

Conforme CARTANA ${ }^{4}$, em seu estudo na localidade da Costa da Lagoa, Florianópolis, "o parto a domićlio é lembrado pelas mulheres como algo diffcil e envolvendo muito sof rimento". E portanto, nesta localidade atualmente, quase todas as mulheres preferem ir à maternidade na hora do parto. Esta valorização do parto na maternidade leva à mudança nos costumes no cuidado à criança. Porém, graças ao apoio que a rede familiar e a vizinhança formecem à puérpera no cuidado ao RN e devido ao contato ainda muito limitado e autoritário dos profissionais de saúde, continua havendo muitas vezes, orientações distintas.

$\mathrm{O}$ uso da faixa umbilical também, se insere nesta 
mudança de costume. As poucas mulheres que ainda usam este artifício, dão as seguintes explicações: "Uso para o nenê não ter hérnia". (mulher de 57 anos, 8 filhos, sogra de puérpera). "Uso pro umbigo não ficar saltado". (mulher de 27 anos, 3 filhos, puérpera).

"Para não quebrar o umbigo. É uma proteção prá criança". (mulher de 52 anos, multípra, mãe de puerpera).

As mulheres que disseram que a faixa umbilical está em desuso, ou as que disseram que não a utilizavam, alegaram que "hoje em dia não se usa mais" refletindo assim, a mudança dos costumes. Algumas ainda mostram que entenderam a explicação feita pelos profissionais de saúde: "se eu boto faixa o umbigo sua e fica molhado e ai pode infeccionar". Ainda em relação ao desuso da faixa umbilical, pode-se observar que se baseiam em experiências anteriores: "não uso porque tive a experiência com um sobrinho que ficou todo estufado com a faixa". A faixa umbilical e totalmente contra-indicada pelos profissionais de saúde e pela literatura. MARCONDES ${ }^{11}$ refere que o calor e a umidade criam um ambiente propício para a infecção.

Assim podemos verificar que existem mudanças em curso tanto no que se refere a solução utilizada no curativo do coto, quanto no que se refere a faixa umbilical.

\section{CONSIDERAÇÕES FINAIS}

O estudo da percepção de mulheres sobre suas crenças e práticas no cuidado ao RN enquanto este ainda está com o coto umbilical, nos levam a algumas considerações.

Constatamos que as mulheres experientes da família é que auxiliam e mantém sua influência no cuidado ao RN muito mais do que os profissionais de saúde. Este auxílio irá influenciar nos significados que as mulheres tem acerca do "umbigo", que para algumas significa vida, para outras perigo e morte, para outras ainda tem poder sobre a saúde e doença. Também irá influenciar na forma de cuidar terapeuticamente do "umbigo". Assim, enquanto nas instituições de saúde não se recomenda mais o uso da faixa umbilical, as mulheres ainda a utilizam, por várias razões, da mesma forma que as soluções empregadas no curativo do coto. Apesar dos profissionais de saúde sempre mencionados pelas mulheres entrevistadas em último lugar, podemos verificar que com a maioria dos partos realizados nas maternidades, a influência desta na mudança do hábito vai sendo observada nos cuidados dispensados aos RN.

ROSA ${ }^{16}$ afirma que as percepções que as pessoas tem sobre os cuidados tem grande valor de acordo com o sistema social em que aparecem. Segundo esta autora, para nós profissionais, a maior importância é estabelecer as possíveis relações entre as perceções do indivíduo e suas concepções de saúde. Uma vez compreendidas estas relações poderá ocorrer uma relação enfermeiro-cliente, onde se leve em consideração seus valores, crenças e práticas, fugindo dos esteriótipos.

Tudo isso nos leva a enfatizar que, ao entramos em contato com a gestante nos serviços de pré-natal ou com a puérpera, nas unidades de internação, não podemos ter a pretensão de realizarmos assistência onde se inclui apenas à orientação a esta mulher. Precisamos levar em consideração as pessoas que lhe são mais próximas e que lhe prestam ajuda, compreendendo o que estas pensam sobre o assunto e quais as suas crenças e práticas.

Para finalizar, é importante mencionarmos a advertência de LARGON ${ }^{10}$ referindo-se à saúde das indígenas: "os serviços de saúde adequados requerem mais do que pessoal e materiais. Há necessidade de que os profissionais reconheçam os fatores sócio-culturais na utilização destes serviços, procurando conhecer as concepçōes de saúde da população para haver relações de respeito mútuo".

\section{REFERÊNCIAS BIBLIOGRÁFICAS}

ASSOCIAÇĀO BRASILEIRA DE NORMAS TÉCNICAS. NBR 6023: Referências bibliográficas. Rio de Janeiro: ABNT, 1989, 19p.

2 ARAÚJO, Alceu Maynard. Medicina Rústica. São Paulo: Nacional, 1977.

3 BOEHS, Astrid Eggert. Famlias vivenciando a chegada de um Recém-Nascido. Trabalho apresentado à disciplina Antropologia Médica do curso de mestrado em Antropologia Social. Universidade Federal de Santa Catarina, 1989 (mimeo).

4 CAR T ANA, Maria do Horto Fontoura. Rede e Suporte Social de famílias. Dissertação (mestrado em Enfermagem - Universidade Federal de Santa Catarina, 1988.

5 COSMINSKY, Sheila Childbirth and midwifery on a Guatemala Finca. Medical Anthropology v.1 № 3 p. 70-103, 1977.

6 ELSEN, Ingrid. AL THOFF, Coleta. "Mulheres brasileiras falam sobre o suporte social durante a gravidez. Trabalho apresentado no Second International Nursing Research Conference on Social Support, 1989, Seoul Korea.

7 DALILLA, Augusto. Primeiro banho e primeiro curativo umbilical em recém-nascido normal, praticados no domichlio: Conhecimentos, opiniōes, práticas e temores manifestados por primigestas e por primiparas. Dissertação (mestrado em enfermagem), Escola Paulista de Medicina, São Paulo, 1983.

8 DOUGLAS, Mary, Pureza e Perigo. São Paulo: Perspectiva, 1976.

9 GLASER, G.B. \& STRAUSS, A.L. The discovery of ground theory, Strategies for qualitative research. Chicago: Aldine Publishing, 1967.

10 LANGDON, Esther Jean. Saúde Indigena: a logica do processo de tratamento. Apresentado no Simpósio "Saúde do Índio". Ministério da Saúde, Braślia, 1986 (mimeo)

11 MARCONDES, Eduardo. Pediatria básica. São Paulo: Sarvier, 1986, 1\% volume.

12 MEAD, Margareth. Sexo e Temperamento. São Paulo: Perspectivas, 1988.

13 MINIS TÉRIO DA SAÚDE, Manual de controle de infecção hospitalar. Comissāo de Controle de Infecção Hospitalar. Brasília: Centro de Documentação do Ministério da Saúde, 1985. 
14 MONTICELLI, Marisa \& BOEHS, Astrid Eggert. Percepção das Mâes sobre os cuidados à criança no primeiro mês de vida. IN: Anais (resumo) Encontro de Pesquisa Qualitativa em Enfermagem, 1. São Paulo: 1988.

15 RODRIGUES, José Carlos. Tabu do Corpo. Rio de Janeiro: Achiame, 1983.

16 ROSA, Maria Tereza Leopardi. Análise dos símbolos e a concepçáo de saúde. Trabalho apresentado à disciplina
Antropologia Simbólica do Curso de Mestrado em Antropologia Social, Universidade Federal de Santa Catarina, 1988 (mimeo).

17 SPENCER, Robert. Embriology and Obstetrics in Preindustrial Societies. IN: LANDY, David, (ed) Culture disease and Healing Studies in Medical Anthropo gy. Macmillan Publishing, New York: 1977. 